\title{
脳卒中片麻㾝者における足底感覚への選択的注意が 歩行立脚期での同時収縮に及ぼす影響
}

\author{
Effects of Selective Attention to Plantar Cutaneous Sensation on Muscular \\ Co-contraction during the Stance Phase of Walking by Stroke Patients
}

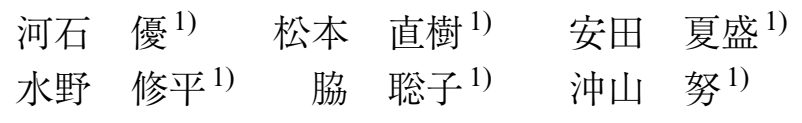

Yu KAWAISHI ${ }^{1)}$, NAOKI MATSUMOTO ${ }^{1)}$, NATSUSHIGE YASUDA ${ }^{1)}$, SHUHEI MIZUNO ${ }^{1)}$, SATOKO WAKI ${ }^{1)}$, TSUTOMU OKIYAMA ${ }^{1)}$

1) Department of Rehabilitation, Kobe Rehabilitation Hospital: 14-1 Nakaichiriyama, Shimotanigamiaza, Yamada-cho, Kita-ku, Kobe-city, Hyogo 651-1102, Japan.TEL+81 78-743-8230 E-mail: yuyakedomo@yahoo.co.jp

Rigakuryoho Kagaku 28(5): 597-600, 2013. Submitted Mar. 15, 2013. Accepted Apr. 19, 2013.

\begin{abstract}
Purpose] The purpose of the present study was to examine the effects of selective attention to plantar cutaneous sensation on muscular co-contraction of stroke patients during the stance phase of walking. [Subjects] Seven sub-acute stroke patients participated in this study. [Method] Subjects were given tasks of discriminating hardness differences of foam rubber with the sole of the paretic side. Electromyograms of the paretic leg during walking were recorded before, immediately after, and $15 \mathrm{~min}$ after the discrimination tasks. The muscular activity and the co-contraction index (CI) during the stance phase were determined. [Result] The muscular activity of the gastrocnemius and $\mathrm{CI}$ of the ankle joint significantly decreased immediately after the discrimination tasks. [Conclusion] These results suggest that selective attention to plantar cutaneous sensation on the paretic side immediately reduces muscular co-contraction of stroke patients during walking.
\end{abstract}

Key words: stroke, gait, co-contraction

要旨：〔目的〕脳卒中片麻瘏者において, 足底感覚への選択的注意が歩行立脚期での麻痺側下肢同時収縮に及ぼす影 響を検討する。〔対象〕脳卒中片麻痺者 7 名.〔方法〕硬さの異なる 4 種のスポンジマットを用い, 座位, 閉眼にて足 底で硬さを弁別する課題を試行した。課題前, 課題直後, 課題 15 分後にて麻痺側下肢の歩行時筋電図を測定し, 立 脚期での筋活動量, co-contraction index $(\mathrm{CI})$ を算出した。〔結果〕課題前に比べ, 課題直後で腓腹筋筋活動量, 足関 節 CI に有意な減少が認められた。〔結語〕脳卒中片麻痺者において, 歩行前の麻痺側足底感覚への選択的注意は, そ の直後の歩行時立脚期での同時収縮を軽減させることが示唆された.

キーワード : 脳卒中, 歩行, 同時収縮

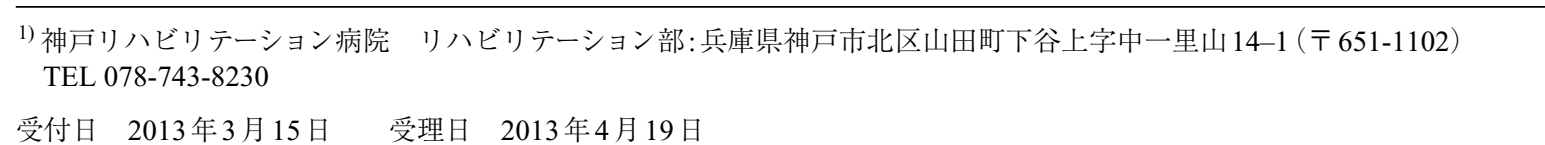




\section{I.はじめに}

動作時に，主動作筋と拮抗筋の過剩な同時収縮が起こ ると, 円滑な関節運動を阻害する ${ }^{1)}$. 脳卒中片麻痺者に おいて, 立位時や歩行時に, 麻瘏側下肢に過剩な同時収 縮が観察され2)，立位姿勢や歩行の安定性を低下させる 一要因となっている.

立位, 歩行時において, 安定した姿勢をとるための適 切な下肢筋活動には足底からの感覚入力が重要である. 足底感覚と歩行時下肢の反応との関連を検討した研究で は，足底感覚機能の低下により，歩行立脚期での下肢筋 活動パターンが変化すると報告されている3,4)

注意が体性感覚情報処理に及ぼす影響については，知 覚対象に対する選択的注意が体性感觉情報処理を促進さ せることが知られている. Iguchi ら5) は示指と中指の同 時刺激に対する一次体性感覚野の脳活動を計測した結果, 一方の指に注意を向けることで，その指だけが刺激され たかのように受容野の活動が調整されることを報告して おり，注意によって不必要な雑音入力がマスキングされ， 必要な情報に対する脳の反応が強化されるとしている。

これらのことから, 脳卒中片麻疩者に扔いて, 歩行前 に足底感覚への選択的注意を行うことで, 歩行時立脚期 に抢ける足底からの感覚情報処理を促進させ, より適切 な筋活動を誘導し，過剩な同時収縮を軽減させることが 考えられる。

本研究では，この仮説を検証することを目的に，硬さ の異なるスポンジマットを使用した足底圧覚弁別課題を 用い，その前後での歩行時筋活動を測定することで，脳 卒中片麻瘏者に扔ける足底圧覚への選択的注意が, 歩行 立脚期での麻疩側下肢の同時収縮に及ほす影響を検討し た。また, 筋活動と同時に, 歩行速度, 歩行中の加速度 変化を測定することで, 歩行安定性の程度を検討した。

\section{II. 対象と方法}

\section{1. 対象}

対象は回復期病棟に入院中であり，以下の選定条件を
満たす脳卒中片麻痺者 7 名とした。すなわち，初発の大 脳一側病変であるもの, $10 \mathrm{~m}$ の歩行が杖などの補助具 を使用することなく自立しているもの,コミュニケーショ ンに問題がないもの，歩行に影響する骨関節疾患の既往 がないものとした，また，本研究では，歩行時の麻痺側 下肢に過剩な同時収縮が起こるものを対象とするため, 麻痺側足関節背屈の他動運動時にみられる抵抗感を modified Ashworth scale ${ }^{6}$ を用いて評価し，その值が0 のもの（筋緊張に元進がみられないもの）は対象から除 外した。 さらに, 麻痺側足底への選択的注意を必要とす るため, 麻疩側足底の表在感覚に著明な感覚障害がある ものも対象から除外した，対象者についての詳細な情報 を表 1 に示す，対象者には本研究の内容について，書面， 及び口頭にて十分な説明を行い，本人の署名を以って同 意を得た。

\section{2. 方法}

足底圧覚弁別課題は, 硬さの異なる 4 種のスポンジマッ 卜を用いて行い，座位，閉眼状態にて麻疩側足底を久ポ ンジマット上に乗せ，硬さの弁別を求めるものとした77. スポンジマットは同一の素材を用いて作成し，厚さを $1 \mathrm{~cm}, 2 \mathrm{~cm}, 3 \mathrm{~cm}, 4 \mathrm{~cm}$ とすることで 4 種類の硬さを

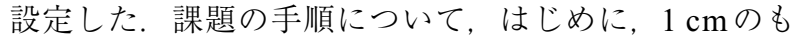
のから順に 4 種全てのスポンジマットの硬さを足底で知 覚し，どのスポンジマットが使用されたかについての言 語フィードバックを与え，各スポンジマットの硬さを記 憶するよう求めた，その後，任意に作成されたランダム 表に基づいて 20 回連続して足底での硬さの弁別を行なっ た、ランダム表は, 20 回の試行内で各硬度のスポンジマッ トがそれぞれ5回ずつ出現するように設定して作成した． 弁別課題中，試行ごとに口頭にて回答を求め，その正誤 を記録した。その際，被験者に結果の正誤に関する知識 は与えなかった

歩行は弁別課題の即時的効果，持続的効果を検討する ため, 弁別課題前, 課題直後, 課題 15 分後の 3 回で行い, その際の麻疩側下肢筋活動，加速度变化を測定した。ま た, 歩行は快適歩行とし, $10 \mathrm{~m}$ 歩行時間をストップウォッ

表 1 対象者情報

\begin{tabular}{ccccccccc}
\hline ID & 年齢 & 性別 & 罹患日数 & BRS $^{\mathrm{a}}$ & 診断名 & 麻痺側 & MAS 足/膝 $\mathrm{b}$ & 歩行速度 $\mathrm{c}$ \\
\hline 01 & 33 & 男 & 122 & $\mathrm{~V}$ & 脳梗塞 & 左 & $2 / 1+$ & $0.28 \mathrm{~m} / \mathrm{s}$ \\
02 & 74 & 男 & 128 & $\mathrm{~V}$ & 脳出血 & 左 & $1+/ 1$ & $0.26 \mathrm{~m} / \mathrm{s}$ \\
03 & 63 & 女 & 154 & $\mathrm{IV}$ & 脳出血 & 左 & $1 / 1$ & $0.32 \mathrm{~m} / \mathrm{s}$ \\
04 & 67 & 男 & 134 & $\mathrm{~V}$ & 脳出血 & 右 & $1 / 1$ & $0.08 \mathrm{~m} / \mathrm{s}$ \\
05 & 55 & 女 & 145 & $\mathrm{III}$ & 脳出血 & 左 & $1+/ 1$ & $0.29 \mathrm{~m} / \mathrm{s}$ \\
06 & 70 & 男 & 108 & $\mathrm{~V}$ & 脳出血 & 右 & $2 / 1+$ & $0.37 \mathrm{~m} / \mathrm{s}$ \\
07 & 64 & 女 & 169 & IV & 脳梗塞 & 右 & $1+/ 1$ & $0.39 \mathrm{~m} / \mathrm{s}$ \\
\hline
\end{tabular}

a: Brunnstrom recovery stage, b: modified Ashworth scale 足関節背屈/膝関節伸展, $\mathrm{c}$ : 快適歩行 速度 (歩行補助具使用なし)。 
チにて測定した。

歩行時の筋活動計測には EMG 携帯測定システム （Biometrics社, PS850) を使用し, 導出筋を麻痺側下肢 の前脛骨筋，腓腹筋（内側頭），大腿直筋，大腿二頭筋 とした，電極は表面電極（Biometrics社，SX23091000； 電極間距離: $2.0 \mathrm{~cm}$ ) を使用し, 十分な皮膚処理を行なっ た後, 各筋の走行に沿って筋腹に貼付した。 また, 麻瘏 側足底の踵部と拇趾球部に感圧センサー（Biometrics 社, PH9462）を貼付し，それから得られた信号により歩行 中の立脚期を同定した，全ての記録についてサンプリン グ周波数は $1000 \mathrm{~Hz}$ とした。

得られた筋電図信号は, 通過帯域 10-300 Hzのバンド パスフィルタによる処理を行った後，15秒間の安静立位 時に扔ける平均筋活動量で正規化した，その後，歩行立 脚期に㧍ける筋活動量として, 立脚期中の平均筋活動量 を各筋について算出した，さらに，立脚期に扔ける同時 収縮の指標として Falconer ら ${ }^{8)}$ が推奨する co-contraction index $(\mathrm{CI})$ を足関節，滕関節について求めた，CIの算 出式を以下に記す。

$$
\begin{gathered}
I_{\alpha}=\int_{t_{1}}^{t_{2}} E M G_{\text {agon }}(t) d t+\int_{t_{2}}^{t_{3}} E M G_{\text {ant }}(t) d t \\
I_{\text {total }}=\int_{t_{1}}^{t_{3}}\left[E M G_{\text {agon }}+E M G_{\text {ant }}\right](t) d t \\
C I=\frac{2 I_{\alpha}}{I_{\text {total }}} \times 100
\end{gathered}
$$

算出式について, $\mathrm{t}_{1}$ から $\mathrm{t}_{2}$ は主動作筋の筋活動量が拮 抗筋よりも小さい区間, $\mathrm{t}_{2}$ から $\mathrm{t}_{3}$ は拮抗筋の筋活動量が 主動作筋よりも小さい区間を示す。また， $\mathrm{I}_{\mathrm{total}}$ は主動作 筋と拮抗筋の筋電図積分値を足した值を表している。 こ れらの算出式より，CIは，その值が大きいもの程，よ り強い同時収縮がなされたことを示している。

な㧍，足関節のCIについては前脛骨筋と腓腹筋の筋 電図, 膝関節のCIについては大腿直筋と大腿二頭筋の 筋電図に基づいて算出した。 また，各被験者に抒ける平 均筋活動量, CIは, 歩行開始から 10 歩行周期までの值
の平均值とした。

歩行時における加速度变化の測定には，3軸加速度計 （Biometrics社，ACL300）を使用した。装着部位は第3 腰椎突起部とし, サンプリング周波数は $1000 \mathrm{~Hz}$ とした。 加速度計より得られたデータから，10 $\mathrm{m}$ 歩行時におけ るX方向 (左右方向), Y方向（上下方向）の root mean square（RMS）を算出した。加速度 RMS は身体動摇の程 度を示しており, 歩行時の不安定性を示す指標として有 用であるとされている9).

統計解析は多重比較検定 (Bonferroni) を用い, 各算出 項目について課題前, 課題直後, 課題 15 分後で比較した. また, 弁別課題中に起きた知覚学習の程度を検討するた め, 20 試行の弁別課題内での最初の 5 試行と最後の 5 試 行について，その正答数をWilcoxonの符号付き順位検 定を用いて比較した。有意水準は 5\%とした。

\section{III. 結 果}

3 試行の歩行時に抢ける各算出項目の結果を表 2 に示 す. CIについて, 足関節の值に扔いて, 課題前に比心 課題直後で有意に減少していた，筋活動量では，腓腹筋 の值に扔いて, 課題前に比べ課題直後で有意に減少して いた. $10 \mathrm{~m}$ 歩行時間, 加速度 $\mathrm{RMS}(\mathrm{X}$ 方向, $\mathrm{Y}$ 方向)では, 各歩行間で有意な差は認められなかった。

弁別課題内での最初の 5 試行と最後の 5 試行の正答数 では, 最初の 5 試行が $3.0 \pm 0.8$, 最後の 5 試行が $3.1 \pm 0.8$ であり, 両群間に有意な差は認められなかった。

\section{IV. 考 察}

弁別課題の正答数に打ける比較結果について, 最初の 5 試行と最後の 5 試行で有意な差は認められなかった. これは, 弁別課題の前後で足底感覚機能に変化がないこ とを示しており, 本研究の結果示された弁別課題後の筋

\begin{tabular}{|c|c|c|c|c|c|}
\hline & & 課題前 (a) & 課題直後 (b) & 課題 15 分後 (c) & 比較結果 \\
\hline \multirow[t]{2}{*}{ CI (\%) } & 足関節 & $37.0 \pm 7.9$ & $34.3 \pm 8.0$ & $34.4 \pm 9.4$ & $* \mathrm{~b}<\mathrm{a}$ \\
\hline & 膝関節 & $42.8 \pm 7.5$ & $43.5 \pm 8.1$ & $45.0 \pm 8.5$ & \\
\hline \multirow[t]{4}{*}{ 筋活動量 (\%/s) } & 前脛骨筋 & $895 \pm 574$ & $874 \pm 427$ & $901 \pm 477$ & \\
\hline & 腓腹筋 & $289 \pm 108$ & $252 \pm 98$ & $268 \pm 121$ & $* \mathrm{~b}<\mathrm{a}$ \\
\hline & 大腿直筋 & $417 \pm 436$ & $437 \pm 484$ & $483 \pm 598$ & \\
\hline & 大腿二頭筋 & $607 \pm 737$ & $416 \pm 465$ & $227 \pm 83$ & \\
\hline 10 m歩行時間（s） & & $46.3 \pm 37.6$ & $50.4 \pm 42.5$ & $46.3 \pm 40.2$ & \\
\hline \multirow[t]{2}{*}{ 加速度 RMS } & $\mathrm{x}$ 方向 & $0.014 \pm 0.005$ & $0.014 \pm 0.006$ & $0.015 \pm 0.006$ & \\
\hline & Y方向 & $0.095 \pm 0.005$ & $0.094 \pm 0.004$ & $0.094 \pm 0.005$ & \\
\hline
\end{tabular}
活動の変化が, 知覚学習による足底感覚機能の向上に由

表 2 各算出項目の結果

mean $\pm \mathrm{SD}, \quad * \mathrm{p}<0.05$. 
来するものではなく, 足底感覚に対して選択的注意を行 なった結果であると考えられる。

CIの比較結果について, 課題前に対し課題直後で足 関節の值が有意に低值を示した。これは，足底感覚に対 する選択的注意課題が, その後の歩行における立脚期で の感覚情報処理過程に影響を及ぼし，それによって，床 面への身体支持に対する過剩な同時収縮が軽減されたこ とを示唆している.

筋活動量の比較結果では, 課題前に対し課題直後で腓 腹筋の值が有意に低值を示した。近年, 足底からの皮膚 感覚入力により, ヒラメ筋の伸張反射が抑制されること が報告されている10)。このことから，本研究において， 弁別課題直後の腓腹筋活動量の減少は, 足底感覚への選 択的注意によって足底からの感覚入力が促進され, 立脚 期での腓腹筋伸張反射がより抑制された結果と考えられ る. また, 弁別課題直後における足関節 CI の減少は, この腓腹筋伸張反射の抑制に起因していることが示唆さ れる.しかし, これらの点については, 筋活動量といっ た運動力学的な結果からでは断定することはできず，推 測の域を出ない. それについては, 今後, H反射の測定 など電気生理学的手法を用いて検討する必要がある。

また, これらのCI, 筋活動量の変化は弁別課題直後 のみに観察され, 課題 15 分後には有意差が認められなかっ た。これは, 足底感覚への選択的注意がその直後の歩行 時筋活動のみにしか影響を及ぼさないことを示している。

一方，大腿二頭筋の筋活動量についても，腓腹筋同様， 課題前に比べ課題直後, 課題 15 分後で減少傾向にあっ たが，その結果には個人間でばらつきが大きく, 有意差 は認められなかった。 これは, 足底からの感覚入力が歩 行立脚期での筋出力に及ぼす影響について, 腓腹筋に比 べ大腿二頭筋では個人差がより大きく, 一様な筋出力量 の減少を示さなかったためであると考えられる。

$10 \mathrm{~m}$ 歩行時間, 加速度 RMS の結果では, 全ての歩行 で有意な差を示さなかった。これについて, 脳卒中片麻 痺者の歩行は, 麻疩側下肢の過剩な同時収縮の他, 様々 な要因により不安定となる2)。 そのため, 足関節の同時 収縮の軽減のみでは, 歩行全体の安定性を向上させるに は至らなかったと考えられる。

本研究の結果, 脳卒中片麻瘒者において, 足底感覚へ の選択的注意によって, その直後の歩行時立脚期におけ る麻痺側足関節の同時収縮を軽減させることが示された。 これより, 歩行リハビリテーションの際に, 種々のアプロー チに加え, 足底感覚に対する選択的注意を考慮すること で，立脚期での過剩な同時収縮を軽減させ，歩行運動の 再学習をより有効にすることが示唆される.

本研究では, 足底感覚への選択的注意の影響を検討す るため, 足底圧覚弁別課題を用いた。しかし, 本研究の 結果見られた課題直後の筋活動の変化について, 足底感 覚への選択的注意の影響のみならず, 足底をスポンジマッ
トに接触させるといった足底への圧感覚刺激の入力が影 響していた可能性を否定できない。これについては，対 象群を作成し，足底に対し同様の刺激を入力するが，并 別課題を行わず選択的注意を求めないものと比較する必 要がある。

また，今回は足底表在感覚に著明な感覚障害がないも のを対象とした，さらに，麻痺側下肢の筋緊張について は, modified Ashworth scaleが1以上のものを対象とし, 結果, 全対象者の平均が $1.29 \pm 0.48$ と比較的筋緊張の 克進が軽度であるものが対象となった。しかし，本研究 では対象となる脳卒中片麻疩者において, 足底感覚機能 や麻瘏側下肢の筋緊張の程度が, 弁別課題後の筋活動の 変化に影響を及ぼすことが考えられる，今後は，対象者 数を増やすと共に麻瘏側足底に著明な感覚障害を呈する ものも対象とし, 足底感覚機能, 麻瘏側下肢の筋緊張の 程度が筋活動の変化に及ぼす影響をより詳細に検討する 必要があると考える。

\section{引用文献}

1) 小田伸午, 市橋則明: ヒトの動き百話. 市村出版, 東京, 2011, pp116-118.

2) Arene N, Hidler J: Understanding motor impairment in the paretic lower limb after a stroke: a review of the literature. Top Stroke Rehabil, 2009, 16(5): 346-356.

3) Höhne A, Ali S, Stark C, et al.: Reduced plantar cutaneous sensation modifies gait dynamics, lower-limb kinematics and muscle activity during walking. Eur J Appl Physiol, 2012, 112: 3829-3838.

4) Nurse MA, Nigg BM: The effect of changes in foot sensation on plantar pressure and muscle activity. Clin Biomech, 2001, 16(9): 719-727.

5) Iguchi Y, Hoshi Y, Tanosaki M, et al.: Attention induces reciprocal activity in the human somatosensory cortex enhancing relevant- and suppressing irrelevant inputs from fingers. Clin Neurophysiol, 2005, 116(5): 1077-1087.

6) Bohannon RW, Smith MB: Interrater reliability of a modified Ashworth scale of musle of muscle spasticity. Phys Ther, 1987, 67(2): 206-207.

7) Morioka S, Yagi F: Influence of perceptual learning on standing posture balance: repeated training for hardness discrimination of foot sole. Gait Posture, 2004, 20(1): 36-40.

8) Falconer K, Winter DA: Quantitative assessment of cocontraction at the ankle joint in walking. Electromyogr Clin Neurophysiol, 1985, 25(2-3): 135-149.

9) Menz HB, Lord SR, Fitzpatrick RC: Acceleration patterns of the head and pelvis when walking on level and irregular surfaces. Gait Posture, 2003, 18(1): 35-46.

10) Knikou M, Conway BA: Modulation of soleus H-reflex following ipsilateral mechanical loading of the sole of the foot in normal and complete spinal cord injured humans. Neurosci Lett, 2001, 303(2): 107-110. 